Dossiê Especial: Formação Docente, Tecnologias Digitais e Educação Crítica.

ROCHA; HIBARINO e AZZARI (orgs.)

Revista X, vol.2, 2015

\title{
ENSINO DE INGLÊS, TECNOLOGIAS DIGITAIS E RUPTURAS
}

\author{
Digital Technology, English Language Teaching and breaches
}

\section{Eliane Fernandes AZZARI - UNICAMP1}

\begin{abstract}
RESUMO: Pensar a formação em língua inglesa na educação básica nos temposespaços contemporâneos requer avaliar a presença marcadamente favorável à inclusão das TDICs (Tecnologias Digitais da Informação e Comunicação) manifestada por discursos sobre ensino e aprendizagem que circulam - nos mais diversos contextos -, na atualidade. Discursos esses evidenciados, por exemplo, em enunciados dos editais públicos para a escolha de livros e recursos didáticos que relacionam a inserção de TDICs (em suas mais diversas formas, gêneros, modalidades e possibilidades) a ações voltadas à busca por melhorias na educação, apontando para a intersecção entre políticas educacionais para a formação linguística e as tecnologias. Diante do exposto, proponho (re)discutir possíveis interfaces entre a inserção das TDICs nos planejamentos e práticas pedagógicas de professores de inglês que atuam na rede pública e a educação crítica (CHARLOT 2013; BIESTA, 2010), questionando orientações que, à maneira cartesiana, emprestam às tecnologias digitais protagonismo centralizador e autônomo (SELWYN, 2011; 2013; 2014). Orientando o olhar à maneira crítica (LUKE, 2014), problematizo a integração de recursos tecnológicos síncronos e assíncronos às práticas docentes, relacionando-a aos objetivos que norteiam o ensino de língua estrangeira especificamente a língua inglesa - na educação fundamental pública e ao papel agente da docência em tempos de comunicação e informação globalizadas.
\end{abstract}

PALAVRAS-CHAVE: ensino e aprendizagem de inglês; escola pública; educação crítica; letramentos do professor; tecnologias digitais.

ABSTRACT: Thinking about English as a foreign language in the fundamental years of formal schooling in Brazil, within contemporary times-spaces, demands an evaluation of discourses - circulated in a myriad of contexts - which blatantly favor the introduction of Digital Communication and Information Technologies (DCITs) in all teaching and learning related processes. Those discourses might be easily spotted by utterances such as the ones announcing public institutional calls, published by the education minister offices, which are meant to evaluate, select and recommend textbooks and all other sorts of different didactic resources, that connect the insertion of DCITs (in a wide range of genres, forms and modalities) to a prospecting general improvement in public education. Taking it into consideration, this article aims at (re)discussing possible interfaces between the introduction of DCITs in pedagogic planning and practices of English language teachers who work in Brazilian public schools and a critical approach to education, questioning orientations which, submitting to a Cartesian way of thinking, apply to digital technologies some sort of centralizing and autonomous role (SELWYN, 2011; 2014). Assuming a critically oriented point of view (LUKE, 2014), it proposes a discussion around the insertion of technological resources in educational process and its relation to: the main objectives of foreign

\footnotetext{
${ }^{1}$ Doutoranda em Linguística Aplicada pelo IEL / Unicamp e Mestra em Linguística Aplicada pela mesma instituição. Bolsista CNPq. elianeazzari@gmail.com.
} 


\section{Dossiê Especial: Formação Docente, Tecnologias Digitais e Educação Crítica. ROCHA; HIBARINO e AZZARI (orgs.) \\ Revista X, vol.2, 2015}

language teaching in Brazilian regular schools; to a teacher agency role facing communication and information globalized age and to the basic principles for a critically oriented education (BIESTA, 2010, SELWYN, 2013).

KEY-WORDS: English teaching and learning; Brazilian public schools; Critic Education; teacher literacy; digital technologies.

\section{CONSIDERAÇÕES INICIAIS}

Já não há como - e nem porque -, negar a contribuição das Tecnologias Digitais da Informação e Comunicação (TDICs) na reconfiguração dos modos e meios pelos quais as informações podem ser produzidas, circuladas e acessadas nos dias correntes, afetando, por efeito, o traçado das relações humanas. Não raro, a presença de dispositivos móveis (tais quais tablets e aparelhos celulares) ganha cada vez mais destaque nas tarefas e contextos cotidianos - públicos e privados -, como mediadora de práticas sociais tais quais transações financeiras e conversas entre familiares e amigos que, ainda que ocupem espaços físicos distantes, mantêm a "ilusão" da proximidade sustentada, por exemplo, pela presença ubíqua em redes sociais síncronas.

Apoiadas nas e pelas TDICs, surgem frequentemente (novas) diversas práticas de escrita e leitura representadas por gêneros diversos que, via de regra, revelam-se banhados na multimodalidade, multissemioticidade, intertextualidade $\mathrm{e}$ hipertextualidade - características marcantes dos contextos digitais (GEE; HAYES, 2011). Tal reconfiguração nas comunicações / relações humanas não poderia passar despercebida pelos portões das escolas de educação básica sem, também lá, suscitar efeitos.

Muito há ainda que se questionar em termos de quais seriam os objetivos (e meios) efetivos para inserções de tecnologias digitais na educação - o que implica observar de quem partem esses objetivos e a quem atenderiam, por exemplo, (SELWYN, 2011; 2014), mas não é difícil observar que a relação entre as TDICs e os processos de ensino e aprendizagem tem protagonizado discursos que, conclamando mudanças há muito necessárias, associam essas tecnologias à complexa tarefa de renovar a educação fundamental brasileira. Diversos discursos são evidenciados, por exemplo, em enunciados de editais públicos para a escolha de livros e recursos didáticos que relacionam a inserção de TDICs (em suas mais diversas formas, gêneros, modalidades e possibilidades) a ações direcionadas à busca por melhorias na educação, 


\section{Dossiê Especial: Formação Docente, Tecnologias Digitais e Educação Crítica. ROCHA; HIBARINO e AZZARI (orgs.) \\ Revista X, vol.2, 2015}

apontando para a intersecção entre políticas educacionais para a formação linguística e as tecnologias.

Inclinando esta discussão em direção à educação linguística, apoio os questionamentos supramencionados aqui, também, na problematização oferecida por Biesta (2010) que aponta que, em uma época em que as medições escolares (balizadas por exames institucionalizados em âmbitos loco-globais), definem melhores e piores processos educacionais em função de desempenhos tabulados à maneira quantitativa, cabe questionar o que se compreende como melhorias na chamada "qualidade" educacional. Para esse autor, é importante retomar o conceito de qualidade (amplamente explorado e, consequentemente, desgastado, na atualidade) e os objetivos que norteiam a educação, ou seja, balizar o que é educação, quem e o quê se objetiva com ela, assim como (re) visitar que juízos de valor orientam tais objetivos (BIESTA, 2010, p. 19). Nessa direção, novamente, questiono discursos.

Discursos, ou seja, "a língua em sua integridade concreta e viva" (BAKHTIN, 2002, apud BRAIT, [2006]2012, p.11) se materializam na palavra que - contextualizada e (re) significada em e pelo dialogismo nas relações sociais -, é de natureza essencialmente ideológica (BAKHTIN[VOLOVHINOV, 2006 ). Assim, são os discursos (e suas ideologias) que servem como "pontos de partida de como o mundo é organizado e compreendido" (PENNYCOOK, 2006, p.61). Como afirma Rajagopalan "a linguagem humana se encontra visceralmente atrelada a sua atuação política no mundo" (2013, p. 144). Parece-me sensato, dessa forma, questionar pensamentos que, tratando o tema de maneira uniformizada (SELWYN, 2014), se referem às TDICs como se o ato de apropriação desses elementos para práticas didático-pedagógicas fosse, em si mesmo, capaz de gerar e sustentar reformas educacionais.

Assim como Selwyn (2014, s/p), entendo que o "uso educacional das tecnologias digitais precisa ser visto como uma preocupação ideologicamente orientada". Neste ponto, penso que seja preciso destacar os conceitos de tecnologia e ideologia que norteiam esta discussão.

Associadas aos primeiros relatos de presença e manifestações culturais do ser humano na terra, as tecnologias sempre fizeram parte das práticas humanas e, como apontam Verazto et al (2008), conceituar tecnologias implica revisar as múltiplas formas pelas quais o ser humano vem, ao longo de sua história, lançando mão de meios e artefatos diversos para "satisfazer suas necessidades e requerimentos pessoais e coletivos" (2008, p. 


\section{Dossiê Especial: Formação Docente, Tecnologias Digitais e Educação Crítica. ROCHA; HIBARINO e AZZARI (orgs.) \\ Revista X, vol.2, 2015}

78-79). Atualizando a conceituação pelo viés que proponho nesta discussão, questiono que necessidades seriam essas, a que grupo(s) atendem e sob que ponto(s) de vista em relação ao mundo e ao lugar social que ocupam, então, as TDICs estão sendo relacionadas aos processos educacionais contemporâneos. Meu interesse de pesquisa e neste texto se refere, especificamente, à educação em língua estrangeira realizada na esfera escolar pública. $\mathrm{O}$ que me encaminha à apreciação do conceito de ideologia.

Essencialmente política, a língua(gem) é norteada por ideologias que, para Bakhtin (2006), são constituídas por um conjunto de ideias com significados socialmente construídos. Por esse viés, todo discurso é ideologicamente marcado já que as palavras são tecidas a partir de uma multidão de fios ideológicos e servem de trama a todas as relações sociais em todos os domínios. É portanto claro que a palavra será sempre o indicador mais sensível de todas as transformações sociais (BAKHTIN [VOLOCHINOV], 2006, p.40).

Grosso modo, a ideologia, enquanto um construto, podem ser conceituadas como "motivações subjetivas que estão subjacentes" ao uso de formas linguísticas (BAKHTIN [VOLOCHINOV], 2006, p.195). Por conseguinte, toda "preocupação ideologicamente orientada", como destaca Selwyn (2014) em relação às tecnologias, deve ser intensa e criticamente debatida e pesquisada.

Partindo dessa perspectiva, proponho examinar a apropriação das TDICs em práticas escolares / escolarizadas de modo a problematizar o tema, de relevância para a atualidade, tendo em mente a incompletude e o inacabamento típicos da sociedade nos dias correntes, abordando a questão da apropriação de TDICs a partir de uma perspectiva socio-histórico e dirigindo meu olhar em especial à docência de inglês na escola básica pública.

Nesse contexto, advogo pensar em propostas para uma educação linguística que tenham entre seus objetivos a formação crítica voltada à democratização (CHARLOT, 2013; BIESTA, 2010). Nesta vertente, ao reforçar a natureza política da linguagem, compreendo crítica como a "capacidade de percepção que cidadãos têm sobre a sociedade em que vivem" (MONTE MÓR, 2013, p.33).

Seguindo por essa direção, penso que seja possível protagonizar pluralismos (nos âmbitos cultural e social) na construção de uma educação linguística que exercite, também e especialmente, a dúvida sistemática, de modo a precaver-se diante de discursos de repetição, que refletem e refratam visões normalizadoras, assumidas $a$ 


\section{Dossiê Especial: Formação Docente, Tecnologias Digitais e Educação Crítica. ROCHA; HIBARINO e AZZARI (orgs.) \\ Revista X, vol.2, 2015}

priori e a partir do status quo, por perceber que essas orientações tendem a reafirmar desigualdades sociais. Como alerta Selwyn (2014, p. 136), entendo que seja possível identificar elementos promotores / de reforço de desigualdades na maneira como as TDICs têm sido "usadas para a marketirização da educação". Referindo-se a discursos que promovem a visão de "incontáveis benefícios" numa educação mediada pelos recursos digitais, o autor destaque que "um exemplo da desigualdade educacional inerente a esse modelo está no acesso limitado às vantagens sociais que podem ser conquistadas a partir de formas educacionais online" (SELWYN, 2014, p. 136²).

Dessa feita, entendo que seja possível examinar o papel das tecnologias digitais na educação linguística, também em contexto escolar regular, à maneira criticamente orientada, a fim de consider possíveis interfaces com a busca pela ação consciente na construção do papel agente de docentes em serviço. Destaco que, neste contexto, concebo agência como a "capacidade para agir; meu poder para modelar e controlar minha própria vida" (SHIELDS, 2007, p. 7). Ser agente, nesta perspectiva, significaria distinguir-se "por sua vontade de se autoafirmar e marcar seu posicionamento, independentemente do grau do sucesso que tem em sua ousadia" (RAJAGOPALAN, 2013, p. 35).

\section{O PROFESSOR DE LÍNGUA INGLESA, AS TDICs E AS RUPTURAS}

Conquanto a disseminação de discursos em favor da inserção de TDICs nos processos de ensino e aprendizagem de inglês na educação pública seja apresentada neste texto como um fenômeno social e ideologicamente marcado, não é meu objetivo desconstituir de valor a relação dessas tecnologias com a educação linguística. De fato, desejo, através da reflexão ora apresentada, (re)pensar a relação entre o papel agente da docência e sua interface com as escolhas e ações que apontem para o tempo e o lugar das TDICs em processos educativos. A partir dessa perspectiva, destaco o lugar de relevância que a educação exerce mediante "mudanças sociais, diversidade cultural, equidade econômica e a participação política cidadã” (LUKE; FREEBODY, 1997, p. 1).

Nessa direção, acredito que seja possível visualizar a inserção tecnológica à maneira de um movimento em busca da abertura de brechas e/ou rupturas face discursos

\footnotetext{
${ }^{2}$ Todas as traduções de citações diretas de textos em língua inglesa para o português, neste texto, são de responsabilidade da autora.
} 


\section{Dossiê Especial: Formação Docente, Tecnologias Digitais e Educação Crítica. ROCHA; HIBARINO e AZZARI (orgs.) \\ Revista X, vol.2, 2015}

autoritários (BAKHTIN, 1973; SHIELDS, 2007) que frequentemente norteiam e permeiam políticas linguísticas, refletidas em currículos, planejamentos e materiais didáticos e que tendem a normalizar a educação linguística à maneira generalista, desconsiderando, por exemplo, realidades contextuais locais (RAJAGOPALAN, 2013; CANAGARAJAH, 2013).

Falar em educação linguística em inglês ${ }^{3}$ na "escola pública" brasileira também é abrir espaço a generalizações, admito. Há legiões de microcontextos e realidades distintas em meio ao universo geral que tratamos por educação pública no Brasil. Em minhas pesquisas recentes ${ }^{4}$, inseridas no âmbito da escola básica municipal e estadual na região de Campinas, no estado de São Paulo, tenho aprendido que não há mesmo como - e nem é desejável que assim se fizesse - negar a importância de voltar o olhar para as realidades e práticas específicas a cada contexto.

Como aponta Canagarajah (2013, p. 154) contexto é um "construto relativo". Contextos são espaços (no sentido mais amplo, não somente o físico, das paredes e limites geopolíticos) de múltiplas camadas que se sobrepõem. Neles encontramos relações das mais diversas ordens, tais como: culturais (locais e globalizadas/ globalizantes); de identidades (em construção e hibridação); de noções de pertencimento e/ou distanciamento e, inevitavelmente, relações de poder, sendo todas essas relações ideologicamente marcadas. Para pensar a educação linguística nesses contextos, alocados em ambientes institucionais, é preciso, então, manter em mente uma noção desestruturalizante de contexto(s). Porém, ao mesmo tempo, é necessário lembrar que, por ser instituição, a escola (seja ela pública, privada ou comunitária) estará sempre sujeita às hierarquias organizadoras, de tal forma que não se pode igualmente deixar as políticas linguísticas à margem desta discussão.

Rajagopalan (2014, p. 73), discorrendo sobre a importância do entrosamento entre o professor de línguas e a política linguística em voga no país, relembra que "à política linguística concerne uma série de atividades relativas à política, ao

\footnotetext{
3 Oriento-me pela noção de inglês como uma língua que "não tem pátria, nem está delimitada a uma região geográfica". Assim, penso como Rajagopalan que "é esse novo fenômeno linguístico que devemos nos esforçar para ensinar e aprender, porque é dele que os aprendizes de hoje vão precisar no futuro bem próximo" (2011, p.65). Expatriada, essa língua torna-se "ingleses" que podem ser acessados, em sala de aula, pela mediação das TDICs e dos gêneros que apoiam.

${ }^{4}$ Ver Azzari (2013). Também me refiro aqui à minha pesquisa de doutorado, em andamento pelo Instituto de Estudos da Linguagem da Unicamp, em que tenho como tema a discussão que ora trago neste artigo e em que assumo a Pesquisa-ação participativa (REASON; BRADBURY, 2008) como metodologia.
} 


\section{Dossiê Especial: Formação Docente, Tecnologias Digitais e Educação Crítica. ROCHA; HIBARINO e AZZARI (orgs.) \\ Revista X, vol.2, 2015}

planejamento, à planificação, à proteção, à manutenção, ao cultivo e (...) ao ensino da(s) línguas que faz(em) do patrimônio linguístico de um país (...)”. O pesquisador aponta também para o fato de que, antes negligenciada, a dimensão política das línguas (tanto materna quanto estrangeira) tem, finalmente, ganhado o devido lugar de destaque nas questões contemporâneas sobre o ensino e a aprendizagem de línguas. É interessante notar que, conquanto ressalte a importância para que haja um alinhamento do professor com a política linguística vigente, Rajagopalan (2014, p. 74) também aponta para um olhar crítico, conclamando o docente de línguas a contestar e participar de discussões e fóruns públicos em que possa contribuir para a construção das diretrizes e políticas locais e nacionais.

Indo ao encontro dessa perspectiva, pode-se tomar como exemplo de oportunidade para a participação na atual política linguística do país a divulgação da BNCC (Base Nacional Comum Curricular) ${ }^{5}$, cujo anteprojeto foi temporariamente disponibilizado pelos organizadores em espaço digital síncrono. No entanto, trago este exemplo mediante uma importante ressalva.

A participação do professor, pelo fortalecimento do papel agente da docência, é percebida aqui, também, como uma oportunidade para discutir, argumentar e, eventualmente, refutar discursos dos quais não compartilhe - não somente em relação a materiais, métodos e procedimentos, mas também, a políticas educacionais públicas. Neste caso, a ideia de uma base curricular comum em um país cujas dimensões e realidades borbulham em diferenças e diversidades contextuais, como mencionado previamente, não parece coadunar. Por suposto, ao ilustrar uma oportunidade para ruptura representada pelo acesso às tecnologias digitais por intermédio da discussão da BNCC, não estamos postulando concordar, a priori e em condição sine qua non, com um documento dessa ordem. No entanto, para questionar é preciso primeiro informar, conhecer, discutir. É neste sentido, o do exercício criticamente orientado e sistematizado da dúvida, que desejo apontar para a disponibilização e a divulgação da BNCC (e não para o documento em si) como oportunidade para intervenção do professor em processos de ordem educacional, paradigmática e tradicionalmente realizados de maneira verticalizada (de cima para baixo!), como os que se referem às questões

\footnotetext{
${ }^{5}$ Para maiores informações, veja o documento completo em http://basenacionalcomum.mec.gov.br/\#/site/inicio.
} 


\section{Dossiê Especial: Formação Docente, Tecnologias Digitais e Educação Crítica. ROCHA; HIBARINO e AZZARI (orgs.) \\ Revista X, vol.2, 2015}

curriculares. Diante do exposto, ressalva feita, passo à discussão acerca do exemplo sugerido.

Através do acesso via internet, é possível não somente conhecer a proposta da BNCC como também enviar sugestões e comentários. A página do anteprojeto, disponibilizada em ambiente digital, convida a sociedade à interação e à contribuição ${ }^{6}$. Da maneira como vejo, acessar esse documento, à maneira crítica, inserindo-se na discussão e composição de um projeto de dimensão nacional, também faz parte dos processos de intersecção das TDICs com os fazeres pedagógicos do professor, no exercício de sua profissão.

Mais do que um novo instrumento para a efetivação de antigas práticas didáticopedagógicas, as tecnologias digitais, nesse caso, estariam sendo mobilizadas para o exercício da cidadania - ainda que seja para que se manifeste discordância (ou mesmo repúdio) aos conceitos (e mesmo à simples noção) do documento. 0 ambiente síncrono, tempo-espaço mediado pela página disponibilizada na internet, possibilita a contribuição em sua formulação, ou mesmo o questionamento de aspectos ou de seu todo, um exercício dialógico e democrático, reforçado pelo papel dos ambientes digitais na reformulação das comunicações para a participação discursiva e social mais ampla. Resta, no entanto, saber quantos professores poderão efetivamente acessar ao documento que, a meu ver, deveria receber especial atenção nas reuniões semanais de discussão e planejamento acadêmico-pedagógico nas escolas públicas de todo o país (embora em muitas delas, possivelmente, seja necessário fornecer cópias impressas do documento proposto, posto que ainda haja acesso precário, ou mesmo inexistente, aos meios digitais em diversas escolas brasileiras ${ }^{7}$ ). O caminho pode ser tortuoso, mas é possível encontrar / provocar (ainda que pequenas) rupturas.

Sob esse viés, o exercício do papel agente da docência de língua inglesa é percebido, então, como um ato político. Assim como Menezes de Souza (2011, p. 279), entendo que seja preciso destacar as reconfigurações pelas quais tem passado a profissão desse docente "porque mudou ao longo dos anos essencialmente a nossa responsabilidade profissional. Cada vez nos tornamos mais responsáveis sobre nossa

\footnotetext{
${ }^{6}$ Disponível em: http://basenacionalcomum.mec.gov.br/\#/site/interaja?ac=AC LIN. Acesso em 18 set 2015.

7 "Uma pesquisa do Centro de Estudos sobre as Tecnologias da Informação e da Comunicação (Cetic) mostra que apenas7\% dos domicílios no Nordeste possuíam acesso à internet em 2008. Enquanto o Sudeste possuía $25 \%$ dos domicílios conectados, o Sul (20\%), o Centro-Oeste (21\%) e o Norte (7\%)". Fonte: http://www.prodeb.ba.gov.br/modules/news/article.php?storyid=763. Acesso em 07 fev 2015.
} 


\section{Dossiê Especial: Formação Docente, Tecnologias Digitais e Educação Crítica. ROCHA; HIBARINO e AZZARI (orgs.) \\ Revista X, vol.2, 2015}

atuação como educadores". Nessa mesma direção, o pesquisador também aponta para a necessidade de revisão das práticas de sala de aula de inglês como um ato ético em relação ao que podem vivenciar os alunos no mundo globalizado e inundado por TDICs. Nesse universo permeado pela hipertextualidade, a produção, o acesso e a circulação do conhecimento caracterizam-se pela ausência da linearidade que, tradicionalmente, tem configurado a maneira como as aulas - orientadas por currículos estanques e materiais didáticos impressos - são planejadas e apresentadas aos estudantes.

Concordo com Menezes de Souza (2011) que seja um ato de ética profissional contemporânea a tarefa do docente de inglês em desestabilizar a (aparente) segurança oferecida por materiais didáticos e propostas curriculares que, formulados à maneira generalizante e generalizada, tratam alunos e professores como se todos fossem iguais, compartilhadores de identidades, contextos e de realidades sociais e culturais semelhantes, sejam quais forem as partes do Brasil em que se encontram.

Acredito que haja, na inserção criticamente orientada das TDICs, como parte integrante dos processos pedagógicos, uma possibilidade para a quebra da cadeia de discursos (acadêmicos, pedagógicos, curriculares, políticos e mesmo metodológicos) que apagam contextos locais, realidades sociais e que ignoram as mudanças globais, nos processos de educação em língua inglesa. Para tanto, é preciso “abrir os olhos para o fato de que estamos perante novas formas de aprender e ensinar, perante uma forma diferente de se relacionar" (MENEZES DE SOUZA, 2011). Como afirmam Luke e Dooley $(2009$, p.01), as “abordagens orientadas pelo letramento crítico vêm os textos impressos e multimodais, em papel ou digitais - e seus códigos e discursos, como tecnologias humanas para representar e remodelar mundos possíveis".

Por conseguinte, entendo que seja preciso mobilizar a docência para um ensino de inglês que se configure não só compatível com realidades globo-locais de professores e aprendizes, mas igualmente representativo em face às realidades atuais, sem, no entanto, que isto signifique que seja somente através das tecnologias digitais (e dos recursos e espaços que propiciam) que se possa pensar em rupturas nos processos educacionais.

Não obstante seja possível imaginar muitas outras maneiras de romper e desestabilizar paradigmas nessa área, preocupo-me com as formar pelas quais um olhar crítico para essas tecnologias possa orientar opções contemporâneas - isso, obviamente, 


\section{Dossiê Especial: Formação Docente, Tecnologias Digitais e Educação Crítica. ROCHA; HIBARINO e AZZARI (orgs.) \\ Revista X, vol.2, 2015}

quando sejam disponíveis as materialidades necessárias para a inserção das TDICs (tais quais computadores e acesso à internet, entre outros itens).

Mediante as oportunidades de participação e engajamento discursivos oferecidas / mediadas por gêneros diversos promovidos nos/por ambientes digitais (BRAGA, 2013) e em especial aqueles apoiados no uso da internet, evidencia-se, também, a necessidade de promover uma educação linguística pluralista - em termos culturais, de linguagens e mídias -, em que práticas sociais que circulam, por exemplo, através da WEB, possam fomentar as (re)significações discursivas, privilegiando textos (enunciados, no sentido bakhtiniano) multimodais e multissemiotizados (KALANTZIS; COPE, 2012). Como propõe Pennycook (2010), as "práticas são a principal maneira de organização da atividade social diária e [especificamente] as práticas letradas - dentre as outras - ocupam lugar de destaque na organização social no dia-a-dia" (2010, p.14 da edição eletrônica), o que corrobora para a visão discursiva e pluralista do ensino e aprendizagem da língua inglesa, em suas mais diversas formas e expressões.

O ambiente digital síncrono oferece acesso a blogs e páginas situadas em esferas diversas (jornalística; de âmbito narrativo-pessoal; acadêmica, de comunidades de fãs, etc.). Também é possível vislumbrar o acesso a práticas letradas em língua inglesa, no ambiente digital online, pelo ingresso e participação em redes sociais e fóruns de discussão e/ou na elaboração, publicação e comentário interativo em videoblogs, entre outros. Percebe-se, então, a oportunidade para o engajamento de professores e estudantes em letramentos multissemióticos e multimidiáticos, além de brechas para a construção de sentidos a partir dos "ingleses" (CANAGARAJAH, 2013) que circulam por entre vários desses gêneros digitais (AZZARI; CUSTÓDIO, 2013).

Encontrar oportunidades para irromper práticas e discursos educacionais estabilizados, com o apoio das TDICs, não significa, no entanto, abandonar a estabilidade planificada pelos materiais e fazeres didáticos, tradicionalmente estabelecidos, em favor de uma nova ordem de ferramentas e objetos técnicos, agora mediados por aparatos e meios digitais. Isso seria, figurativamente, o mesmo que, durante a caminhada para a construção do conhecimento em língua inglesa, largar um cipó antigo para apoiar-se noutro mais novo sem, no entanto, revisitar os caminhos seguidos ou mesmo onde se deseja / pretende chegar.

Apoiado-me em Selwyn (2011) acredito que, ao problematizar a interface entre educação e tecnologias, não seja possível - e nem desejável - tomar nem um nem outro 


\section{Dossiê Especial: Formação Docente, Tecnologias Digitais e Educação Crítica. ROCHA; HIBARINO e AZZARI (orgs.) \\ Revista X, vol.2, 2015}

elemento como certos, definidos e/ou estabelecidos à priori. Assim, concordo com esse estudioso quando afirma que o enunciado que promete que a tecnologia educacional fará a "criação de uma sociedade mais justa, humana e inclusiva, onde o desenvolvimento e a transformação do ensino e da aprendizagem atenda a tanto a fins sociais e emocionais quanto a econômicos" (SUTHERLAND et al, 2008,p.5, apud SELWYN, 2011, p.32) é, no mínimo, "entusiasticamente ambicioso". ${ }^{8}$ Como já indicado, esperar das tecnologias digitais o cumprimento dessa tarefa significa representá-las de forma tecnicista e autônoma, até porque há inúmeras lacunas entre a retórica discursiva acerca do tema e sua efetivação (práxis, ou seja, ação, execução de ideias e princípios norteadores). De tal forma que, acredito que para encontrar na inserção das TDICs nos fazeres docentes caminhos para rupturas desejadas nos processos de ensino e aprendizagem de inglês seja ainda necessário investir em maior estudo, pesquisa e problematização do tema.

Nessa mesma direção, entendo que seja igualmente preciso não apenas desmistificar discursos acerca dos efeitos das TDICs na educação, mas, também, as próprias práticas pedagógicas decorrentes de sua inserção. Pensar que as tecnologias contemporâneas podem ser a resposta final para as questões educacionais pode indicar, como aponta Charlot (2013, p. 42) que "acha-se que aprender consiste apenas em interconectar elementos em um sistema e conservas traços duráveis desta interconexão (...)", o que, associado às TDICs representaria uma "ilusão tecnicista". Além disso, é preciso considerar diferentes contextos e realidades sociais vivenciados no Brasil, país em que ainda há "computadores [que] chegam a escolas onde não podem ser ligados por causa da situação deplorável da instalação elétrica” (CHARLOT, 2013, p. 43).

Dessa feita, pensar as TDICs no traçado por rupturas educacionais requer moderação e conscientização quanto a realidades históricas de tempos-espaços sociais e equilíbrio para, em última instância, encarar inacabamento, incompletude.

Assim como Gee e Hayes (2011, p. 102) vejo que "a mídia digital permite que amadores construam redes interativas entre si, para produzir conhecimentos fora das instituições formais" e que esse novo paradigma de produção do conhecimento deva ser (criticamente) investigado a fim de repensarmos a maneira como os saberes e o conhecimento circulam na escola. Também encontro apoio no argumento desses autores

\footnotetext{
${ }^{8}$ Todas as traduções de citações diretas de textos escritos em língua estrangeira , apresentadas neste texto, são de minha responsabilidade.
} 


\section{Dossiê Especial: Formação Docente, Tecnologias Digitais e Educação Crítica. ROCHA; HIBARINO e AZZARI (orgs.) \\ Revista X, vol.2, 2015}

quando afirmam que "vivemos num mundo global onde conhecer mais de uma língua é crucial” (2011, p. 104). Nesse sentido, há boas possibilidades, como assegurado anteriormente, para o contato e o desenvolvimento linguístico (entre outras aprendizagens) nos ambientes digitais.

No entanto, para que esses recursos, ambientes, gêneros e meios sejam mobilizados na educação linguística institucional à maneira de rupturas, será preciso que se apresentem não somente como um conjunto de ferramentas e engenhocas tecnicistas, que, sem dúvida, podem ter suas utilidades didáticas e ajudar professores na personalização de práticas didáticas para seus contextos, rompendo (parcialmente) com a linearidade de materiais didáticos homogeneizantes. Não obstante, esses recursos precisam também ser percebidos como oportunidade para rupturas outras, como a contestação e a participação social. Como alerta Kramsch $(2014$, p.12) as novas mídias trouxeram, junto com a reconfiguração nas comunicações, uma "cultura neoliberal global que preza a escolha individual", tornando visível uma "fragmentação cada vez maior nos contextos locais e culturas de uso, onde uma lacuna está crescendo entre os jovens e mais velhos, o rico e o pobre, o idealista e o materialista, os locais monolíngues e os cosmopolitas multilíngues, aqueles que têm acesso à internet e os que não têm”.

Ao professor de inglês da atualidade parece caber, pois, na reconfiguração de sua ética profissional diante desta modernidade tardia, encontrar rupturas didáticopedagógicas, de formação linguística, mas também (e essencialmente) sócio-discursiva que permitam, quem sabe por intermédio da apropriação crítica das TDICs, reconfigurar os tempos-espaços sala de aula da escola pública como movimentos para a construção do conhecimento e do exercício da cidadania. Ler, escrever e comentar textos (no sentido mais amplo do termo) não somente para emitir juízos de valor, comentário opinativo, mas para: questionar-se e reconhecer-se; identificar-se e desconhecer-se; compartilhar e refutar, enfim, não apenas como forma de aquisição e uso de estruturas linguísticas.

Diante de "fronteiras difusas", é preciso que a docência contemporânea (re)avalie não somente materiais e práticas didáticas - no intuito de adequá-los aos letramentos requisitados / propiciados pelas TDICs e a maneira como elas (re)configuram as comunicações - mas, também, seu papel enquanto educadora.

É preciso abrir os olhos e identificar novos objetivos para o ensino de língua estrangeira na escola regular. Isso implica abandonar o apego a antigas visões de 


\section{Dossiê Especial: Formação Docente, Tecnologias Digitais e Educação Crítica. ROCHA; HIBARINO e AZZARI (orgs.) \\ Revista X, vol.2, 2015}

língua/linguagem com destaque à autonomia estrutural e foco em elementos gramaticais isolados, em favor de uma abordagem discursiva. Nesse viés, o trabalho de compreensão e produção oral e de textos multimodais e híbridos favorece e promove a inserção plurilingue de estudantes em práticas mediadas por gêneros diversos, em que possam construir e negociar sentidos.

Para conceber a noção de língua/ linguagem como prática social e historicamente situada, adoto a teoria de enunciação e o dialogismo de orientação bakhtiniana (BAKHTIN, 1997; 2006; [1992]2011). A perspectiva bakhtiniana informa que os gêneros discursivos estão entrelaçados a horizontes espaço-temporais específicos e permeados por ideologias. Por efeito, pensar os objetivos de ensino da língua inglesa na escola regular por essa perspectiva soma ao papel fundamental da educação - que seria o de qualificar os aprendizes, em qualquer faixa etária, através de conhecimentos e criticidade para que possam atuar no mundo - um segundo (não menos importante) objetivo, a que Biesta (2010, p. 20) chama de socialização (destaque do autor). Segundo o pesquisador, "isso tem a ver com as muitas maneiras pelas quais, através da educação, nos tornamos parte de determinadas "ordens" sociais, culturais e políticas", ainda que esse segundo objetivo nem sempre apareça explicitamente nos processos educacionais.

Se, é "a experiência, e não a verdade, o que dá sentido à educação" (LARROSA; KOHAN, 2013) e se é parte dos objetivos dos processos de ensino e aprendizagem de língua estrangeira na escola contemporânea o engajamento em práticas discursivas, parece haver, na inserção crítica das TDICs nos fazeres docentes, diversificadas brechas para que, assumindo seu papel agente, a docência (re)crie o tempo-espaço aula a fim de promover tais experiências.

\section{CONSIDERAÇÕES (QUASE) FINAIS}

Desconstruir visões teóricas e de procedimentos pedagógicos práticos ou o que Morgan e Ramanathan chamam de "desaprendizagem de maneiras internalizadas e habituais de ver e ser; de nomear o mundo e imaginar futuros sociais" (2005, p. 154),

configura-se, portanto, como importante tarefa na docência nos dias correntes. É nesta direção que se percebe a necessidade de encontrar as rupturas que auxiliem docentes de língua inglesa a romper visões orientadas para conteúdos (e sua memorização / reprodução) que tendem à universalização do perfil de professores e aprendizes, ignorando também seus contextos, além de também permitir ao docente, por intermédio 


\section{Dossiê Especial: Formação Docente, Tecnologias Digitais e Educação Crítica. ROCHA; HIBARINO e AZZARI (orgs.) \\ Revista X, vol.2, 2015}

do exercício de sua agência, revisitar procedimentos didático-pedagógicos metodologicamente engessados. É também nesse sentido que penso ser possível vislumbrar um (provável) papel das TDICs que, criticamente inseridas durante os processos de ensino e aprendizagem, poderiam sustentar oportunidades para $\mathrm{o}$ surgimento de práticas socialmente situadas (e contemporaneamente atuantes) em direção ao engajamento discursivo em língua inglesa - configurando, desse modo, as rupturas desejadas.

A discussão entre a interface educação em língua inglesa e TDICs ainda carece, dessa forma, de exaustiva atenção, mente aberta ao questionamento sistematizado e, também, perceber-se que, tanto em termos do conceito de educação quanto ao papel das tecnologias, há ainda que se encontrar mais face a dúvidas desejáveis do que se espera por respostas estáveis, conquanto haja alguns (possíveis) caminhos a traçar com vistas a encontrar água potável que minimize a (interminável) sede por (possíveis) orientações, ainda que instáveis e intermitentes, para os questionamentos que persistirão. Afinal, é o inacabamento, a indagação, que nos move adiante e à construção de novos sentidos sociais.

Lançar mão de uma abordagem crítica da educação e revisitar os propósitos do ensino e da aprendizagem da língua inglesa na escola básica na atualidade, ao dirigir o olhar para a inserção das TDICs são, portanto, premissas a serem incorporadas à formação inicial e continuada de professores.

Se os tempos correntes são de mudanças e reconfigurações nas maneiras pelas quais as relações sociais e de comunicação são estabelecidas, é preciso manter a mente criticamente orientada a fim de que, indo em direção oposta ao que se almeja, a inserção dessas novas tecnologias nas rotinas escolares não represente apossar-se de novas técnicas para a revalidação de antigas práticas validadas, em especial aquelas que reforçam desigualdades, acentuam desequilíbrios e servem à manutenção da exclusão.

Assim como as TDICs permitem o compartilhamento do conhecimento fora dos espaços institucionalmente destinados a esse papel, abrindo lugar para a personalização de processos de aprendizagem e a troca de experiências, elas também podem auxiliar o exercício do papel agente da docência. Mas é igualmente reconhecível que, como em todos os demais discursos, nas tecnologias voltadas à educação também há a orientação ideológica. Por conseguinte, ao lado do letramento digital e da escolarização de novas tecnologias precisará, sempre e em todas as épocas da história humana, permanecer o 


\section{Dossiê Especial: Formação Docente, Tecnologias Digitais e Educação Crítica. ROCHA; HIBARINO e AZZARI (orgs.) \\ Revista X, vol.2, 2015}

exercício da dúvida sistemática: por que e para que inserir novas tecnologias? Ainda que se pense entender de onde vêm e qual seu destino, bem como as relações de poder que representam, de que forma podem contribuir para a forma de ser docente / como a docência se efetiva?

E, fundamentalmente, manter-se em mente de que forma incorporá-las às práticas didáticas, ao planejamento curricular e pedagógico e aos fazeres diários de professores e alunos poderá auxiliar a construir uma sociedade mais justa e humana. Deixo assim, aqui, essas (e outras tantas) questões a serem discutidas vislumbrando, na educação linguística crítica e plural, possíveis meios para a abertura de espaços que permitam oxigenar mentes sociais.

Questionar e desconstruir discursos, ao invés de reproduzi-los apenas, pode contribuir para ações voltadas à busca por dirimir desigualdades nos processos educacionais. Empregar, mediante a educação linguística crítica, esforços em direção ao engajamento discursivo que possibilite acatar diferenças e pluralismos de toda a sorte, igualmente possibilitando o desenvolvimento de identidades multifacetárias, multiletradas e permeadas pelo respeito e a legitimação do direito humano de criar, recriar, negociar, adaptar e transformar realidades sociais.

\section{AGRADECIMENTO}

Agradeço ao CNPQ pela concessão da bolsa de doutorado que possibiliou a realização desta pesquisa

\section{REFERÊNCIAS}

AZZARI, E. F. O desafio de progredir na aprendizagem da língua inglesa na escola pública: dando voz aos alunos do Ensino Fundamental II. 2013. 131 p. Dissertação (Mestre). Instituto de Estudos da Linguagem, Universidade Estadual de Campinas, Campinas, 2013a.

AZZARI, E. F.; CUSTÓDIO M. Fanfics, Google Docs, a produção textual colaboratia. In: ROJO, R. (org.) Escola Conectada - os multiletramentos e as TICS. São Paulo: Parábola, 2013, p. 73 - 92.

BAKHTIN, M. Problems of Dostoevsky's poetics. Ann Arbor, MI: Ardis, 1973.

Metodologia das Ciências Humanas. In: Estética da criação verbal (6 ${ }^{\mathrm{a}}$ ed).

Tradução de Paulo Bezerra, São Paulo: Martins Fontes, 2011, p. 393-410.

BAKHTIN, M./VOLOCHÍNOV, V. N. Marxismo e filosofia da linguagem. 12. ed. Tradução do inglês de Paulo Bezerra. São Paulo: Hucitec, 2006 [1929].

BIESTA, G. Against learning. Reclaiming a language for education in an age of learning. Nordisk Pedagogik, v. 25, p.54-66, 2005.

. Good education in an age of measurement: on the need to reconnect with the question of purpose in education. Education Assessment, Evauation and Accountability. v. 21, p. 33-46, 2009.

Good education in an age of measurement. Ethics, politics, democracy. London:

Paradigm Publishes, 2010. 


\section{Dossiê Especial: Formação Docente, Tecnologias Digitais e Educação Crítica. ROCHA; HIBARINO e AZZARI (orgs.) \\ Revista X, vol.2, 2015}

BRAGA, D. B. Ambientes Digitais - reflexões teóricas e práticas. São Paulo: Cortez, 2013. CANAGARAJAH, S. Translingual Practice - Global Englishes and Cosmopolitan Relations. New York: 2013.

CHARLOT, B. A mistificação pedagógica. - realidades sociais e processos ideológicos na teoria da educação. Trad. de Maria José do Amaral Ferreira. São Paulo: Cortez, 2013 [2003].

GEE, J. P.; HAYES, E. R. Language and Learning in the Digital Age. Oxon /New york: Routledge, 2011.

KALANTZIS, M.; COPE, B. New learning - Elements of a science of education ( $2^{\text {nd }}$ ed.). Cambridge: CUP, 2012.

KRAMSCH, C. Por que os professores de língua estrangeira precisam ter uma perspectiva multilíngue e o que isto significa para sua prática de ensino.Trad. de Silvana A. C. do Prado. In: CORREA. D.A.(org.) Política linguística e ensino de língua.Campinas: Pontes, 2014.

LARROSA, J; KOHAN, W. Apresentação da coleção. In: BIESTA, G. Para além da aprendizagem. Educação democrática para um futuro humano. Tradução de Rosaura Eichemberg. Belo horizonte / São Paulo: Autêntica, 2013.

LUKE, A. Regrounding critical literacy: representation, facts and reality. In: Hawkins, M. (ed.). Framing Languages and Literacies: Socially Situated Views and Perspectives. New York: Routledge, 2013.

Defining Critical Literacy. In: PANDYA, J. Z.; ÁVILA, J. (eds.). Moving Critical Literacies forward. New York: Routledge, 2014, p.19-31.

LUKE, A.; FREEBODY, P. (eds).Constructing critical literacies: teaching and learning textual practice. Cresskill, NJ: Hampton Press, 1997.

MENEZES DE SOUZA, L. M. T. Para uma redefinição de Letramento Crítico: conflito e produção de Significação. In: MACIEL, R. F.; ARAUJO, V. de A. (Orgs.). Formação de professores de línguas: ampliando perspectivas. Jundiaí: Paco editorial, 2011.

MONTE MÓR, W. Crítica e Letramentos Críticos: Reflexões Preliminares. In: ROCHA, C. H.; MACIEL, R. F. Língua estrangeira e formação cidadã: por entre discursos e práticas. Campinas: Pontes, 2013, p. $31-50$.

PENNYCOOK, A. Postmodernism in Language Policy. In: RICENTO, T. (ed.) An Introduction to Language Policy, Theory and Method, Maiden: Blackwell, 2006, p. 60 -76.

Language as local practice. New York: Routledge, 2010. E-book.

RAJAGOPALAN, K. Vencer barreiras e emergir das adversidades com pleno êxito, sempre com o pé no chão. In: LIMA, D. C. de. (org.) Inglês em escolas públicas não funciona? Uma questão, múltiplos olhares. São Paulo: Parábola, 2011, p.55-65.

Política de ensino de línguas no Brasil: história e reflexões prospectivas.

In: MOITA LOPES, L. P. Linguística Aplicada na Modernidade Recente. São Paulo: Parábola, 2013, p.146-161.

O professor de línguas e a suma importância do seu entrosamento na política linguística de seu país. In: CORREA. D.A.(org.) Política linguística e ensino de língua. Campinas: Pontes, 2014.

REASON, P.; BRADBURY, H. (eds.). Handbook of action research. Participative Inquiry and Practice. Los Angeles: Sage, 2008.

SHIELDS, C. M. Bakhtin. New York: Peter Lang, 2007.

SELWYN, N. Education and Technology - key issues and debates. London / New York,: Continuum, 2011.

Distrusting educational technology - critical questions for changing times. New

York: Routledge, 2014.

VERASZTO , E. V.; SILVA, D.; MIRANDA , N. A.; SIMON, F. O. Tecnologia: Buscando uma definição para o conceito. Revista PRISMA.COM, n.7, p. 60-85, 2008. Disponível em: http://revistas.ua.pt/index.php 